\title{
PENGARUH SKEMA KOMPENSASI TERHADAP KINERJA DENGAN VARIABEL MODERATOR LOVE OF MONEY
}

\author{
Lalitya Nareswari Wibowo \\ Prodi Akuntansi Unversitas Negeri Yogyakarta \\ lalityanareswari@yahoo.co.id \\ Sukirno \\ Staf Pengajar Jurusan Pendidikan Akuntansi Universitas Negeri Yogyakarta
}

\begin{abstract}
Abstrak : Pengaruh Skema Kompensasi Terhadap Kinerja Dengan Variabel Moderator Love Of Money. Penelitian ini bertujuan untuk mengetahui: (1) pengaruh skema kompensasi yang terdiri dari skema bonus, skema denda, skema bonus dan denda, serta skema clawback terhadap kinerja, dan (2) pengaruh moderasi love of money pada skema kompensasi yang terdiri dari skema bonus, skema denda, skema bonus dan denda, serta skema clawback terhadap kinerja. Penelitian ini adalah penelitian eksperimen dengan menggunakan desain faktorial 5x2. Instrumen yang digunakan yakni kuesioner dan aplikasi Performance Program. Hipotesis penelitian diolah menggunakan alat uji statistik two ways ANOVA. Hasil penelitian ini adalah (1) skema kompensasi bonus, skema kompensasi denda, skema kompensasi bonus dan denda, serta skema kompensasi clawback memiliki pengaruh pada kinerja, dan (2) love of money memiliki pengaruh moderat pada skema kompensasi bonus dan skema kompensasi clawback terhadap kinerja.
\end{abstract}

Kata kunci: skema kompensasi, bonus, denda, clawback, love of money, kinerja

\begin{abstract}
The Effect Of Compensation Scheme To Performance With Moderator Variable
Love Of Money. The purposes of this research were to find out: (1) the effect of compensation scheme which consist of bonus scheme, penalty scheme, combination of bonus and penalty scheme, and clawback scheme to performance, and (2) the moderating effect of love of money on compensation scheme which consist of bonus scheme, penalty scheme, combination of bonus and penalty scheme, and clawback scheme to performance. This research was experiment research that used 5x2 factorial design. The instruments used were questionnaire and Performance Program Aplication. The hypothesis's research was processed with two ways ANOVA. The results of this research were (1) bonus compensation scheme, penalty compensation scheme, combination of bonus and penalty compensation scheme, and clawback compensation scheme had an effect on performance, and (2) love of money had a moderate effect on bonus compensation scheme and clawback compensation scheme to performance.
\end{abstract}

Keywords: compensation scheme, bonus, penalty, clawback, love of money, performane 


\section{JURNAL NOMINAL / VOLUME V NOMOR 2 / TAHUN 2016}

\section{PENDAHULUAN}

Salah satu aspek yang paling penting untuk perusahaan adalah sumber daya manusia. Manusia atau karyawan di dalam perusahaan berkontribusi untuk mencapai tujuan perusahaan. Untuk mencapai tujuan perusahaan karyawan memberikan usahanya dalam bentuk kinerja. Kinerja merupakan hasil atau prestasi yang dicapai dalam melaksanakan suatu pekerjaan (Nawawi, 2006: 62). Untuk mewujudkan kinerja yang baik perlu adanya kerjasama dengan pihak baik di dalam maupun di luar perusahaan. Karyawan bekerja sesuai dengan tanggung jawab dan wewenang yang diberikan, selanjutnya perusahaan akan memberikan timbal balik dalam bentuk kompensasi atas usaha yang sudah diberikan oleh karyawan.ompensasi adalah imbalan yang diberikan kepada karyawan atas kerja yang diberikannya untuk organisasi atau perusahaan (Kadarisman, 2012: 1).

Perusahaan menerapkan berbagai strategi kompensasi untuk menarik minat karyawan dan meningkatkan kinerja mereka demi kemajuan perusahaan. Kompensasi yang banyak diterapkan oleh perusahaan adalah berupa sistem imbal jasa (reward) dan hukuman (punishment). Reward yang diberikan dapat berupa bonus dan berbagai macam tunjangan. Sementara itu, sistem punishment yang diterapkan bisa berupa denda dan clawback.
Pada sistem kompensasi berupa bonus, denda, dan clawback, identik dengan imbalan moneter. Bonus diberikan apabila karyawan mampu mencapai atau melampaui target yang ditentukan oleh perusahaan. Denda akan dikenakan kepada karyawan apabila tidak dapat mencapai target, sedangkan clawback adalah situasi dimana bonus yang sudah diberikan kepada karyawan dapat ditarik kembali oleh perusahaan.

BI merupakan salah satu perusahaan yang menerapkan sistem kompensasi yang baik. Menurut data terakhir gaji maksimal pegawai BI tahun 2012 yang dirangkum oleh Detik Finance (2014), gaji asisten pelaksana bernominalkan Rp6.150.000,00; gaji staf sebesar Rp12.720.000,00; gaji asisten manajer sebesar Rp17.720.000,00; dan gaji manajer Rp26.180.000,00. Gaji tersebut belum termasuk kenaikan masingmasing 7\% di tahun 2013 dan 2014 serta tunjangan seperti insentif (berdasarkan kinerja), Tunjangan Hari Raya, tunjangan cuti, dan tunjangan lembur (untuk staf ke bawah).

Keberhasilan sistem kompensasi yang baik juga dibuktikan oleh PT Danone Dairy Indonesia (DDI). PT DDI menerapkan sistem grading dimana grading 1-10 untuk karyawan level staf ke atas dan grading 1114 untuk level bawah. Strategi kompensasi PT DDI adalah berupa konsep 3P, yakni Pay for Position, Pay for Person, dan Pay 


\section{JURNAL NOMINAL / VOLUME V NOMOR 2 / TAHUN 2016}

for Performance. Dengan memberikan kompensasi dan benefit lainnya disertai dengan program pelatihan dan pengembangan karyawan, PT DDI berhasil mencapai mencapai zero turnover untuk karyawan pada level 11-14. Selain itu, melalui program-program tersebut PT Danone Dairy Indonesia memperoleh prestasi berupa ISO 22.000 tentang Food Safety Management System (PortalHR.com, 2009).

Namun di sisi lain terdapat perusahaan yang memiliki masalah dalam pemberian kompensasi sehingga berdampak pada kinerja karyawan dan operasional perusahaan. Sistem kompensasi yang dirasa kurang dan tidak tepat akan menyebabkan turunnya kepuasan karyawan. Karyawan yang merasa tidak puas akan mengalami penurunan semangat dan gairah kerja. Keluar dari perusahaan dan mencari pekerjaan baru dimana kompensasi yang diberikan lebih tinggi akan menjadi pilihan karyawan untuk memperoleh kepuasan mereka Hal demikian nantinya berdampak pada kinerja perusahaan dan melemahkan daya saing perusahaan (Kadarisman, 2012: 27)

Salah satu contoh kasus kompensasi adalah PT Freeport Indonesia (PTFI). Ratusan pegawai PT Freeport Indonesia memblokade jalan di Distrik Tembagapura pada bulan Maret 2015. Mereka menuntut janji perusahaan untuk memberikan insentif lebih, bonus selama empat bulan, dan promosi (Energy Today, 2015).

Melihat contoh penerapan kompensasi oleh beberapa perusahaan di atas maka dapat dikatakan bahwa kompensasi bukanlah persoalan yang sederhana. Kompensasi cukup kompleks untuk diterapkan oleh sebuah perusahaan terutama dengan mempertimbangkan faktor-faktor lain baik yang berasal dari karyawan maupun manajemen. Perusahaan harus mempunyai pedoman yang jelas untuk menetapkan dan menyalurkan kompensasi secara tepat.

Dari sisi karyawan, pastinya mereka ingin mendapatkan kompensasi yang tinggi untuk memenuhi kebutuhan hidupnya sedangkan dari sisi perusahaan ingin menekan biaya yang terlalu tinggi. Kompensasi harus memiliki manfaat yang lebih besar daripada biaya yang dikeluarkan oleh perusahaan. Masalah tersebut dapat dipecahkan dengan trade off antara besarnya kompensasi karyawan dan biaya tenaga kerja yang ditanggung perusahaan (Kadarisman, 2012: 117).

Kompensasi biasanya diberikan dalam bentuk uang. Uang dipandang sebagai motivator utama alasan seseorang untuk bekerja. Uang akan menjadi motivator yang lebih kuat dengan mengkaitkannya dengan prestasi yang diraih sehingga seberapa besar uang adalah seberapa tinggi prestasi dan kinerja yang 


\section{JURNAL NOMINAL / VOLUME V NOMOR 2 / TAHUN 2016}

dilakukannya (Anoraga dan Suyati, 1995: 87).

Pekerjaan seorang karyawan tidak jauh berbeda sama halnya dengan pekerjaan mahasiswa. Mahasiswa menyelesaikan tugas yang diberikan secara mandiri. Mahasiswa dituntut aktif dan selalu berinisiatif. Mahasiswa juga memiliki tanggung jawab seperti layaknya karyawan. Rasa tanggung jawab menuntut mahasiswa untuk menyelesaikan tugas dengan benar dan tepat pada waktunya.

Berkaitan dengan pekerjaan karyawan dan mahasiswa, dapat disimpulkan usaha yang mereka lakukan sama-sama merupakan kinerja. Mereka menyelesaikan tugas yang diberikan kemudian mencapai suatu hasil atau prestasi. Karyawan akan mendapatkan imbal jasa berupa kompensasi sedangkan mahasiswa akan mendapatkan imbalan berupa nilai.

Peneliti memandang sistem kompensasi berupa moneter atau uang sangat penting untuk mencapai kinerja yang memuaskan. Uang tidak hanya dapat digunakan sebagai alat pembelian, tetapi dapat pula menjadi simbol tertentu bagi seseorang. Oleh karena itu, peneliti menggunakan variabel kecintaan terhadap uang sebagai variabel moderator penelitian.

Uang juga merupakan hal penting yang digunakan manusia dalam kehidupan sehari-hari. Uang tampak menarik bagi mereka yang berusia muda. Banyaknya kebutuhan dan keinginan pada usia muda menjadikan uang sebagai hal yang penting untuk memenuhinya. Selain itu, uang juga digunakan oleh mereka untuk pemenuhan kebutuhan atau persiapan di masa mendatang.

Uang juga merupakan hal yang penting bagi mahasiswa terutama mahasiswa yang mempelajari Akuntansi. Akuntansi menggunakan nilai uang sebagai media pembelajaran sehingga mahasiswa sudah terbiasa dengan kata uang. Hal demikian dapat menimbulkan perasaan cinta terhadap uang atau love of money pada mahasiswa.

Berlandaskan hal tersebut maka permasalahan yang diteliti adalah (1) bagaimana pengaruh skema kompensasi terhadap kinerja, dan (2) bagaimana love of money memoderasi pengaruh skema kompensasi terhadap kinerja. Selanjutnya penelitian ini memiliki tujuan untuk mengetahui: (1) pengaruh skema kompensasi terhadap kinerja, dan (2) untuk mengetahui pengaruh moderat love of money pada pengaruh skema kompensasi terhadap kinerja.

Manfaat secara teoritis dari penelitian ini adalah sebagai bahan referensi dan memperkaya wacana ilmiah untuk pengembangan karya ilmiah selanjutnya, khususnya pada bidang akuntansi 


\section{JURNAL NOMINAL / VOLUME V NOMOR 2 / TAHUN 2016}

manajemen dan akuntansi keperilakuan. Manfaat secara praktis untuk para praktisi bisnis adalah sebagai bahan pertimbangan dalam pembuatan kebijakan dan pengambilan keputusan serta pengembangan SDM untuk meningkatkan kinerja melalui sistem kompensasi yang tepat.

\section{METODE PENELITIAN}

Desain penelitian yang digunakan adalah studi eksperimen. Peneliti memanipulasi beberapa variabel kemudian mengamatinya dan mengobservasi efeknya pada responden (Hartono, 2013: 119). Variabel yang dimanipulasi adalah variabel independen yakni skema kompensasi dan variabel yang diamati efeknya adalah variabel dependen yaitu kinerja, dengan love of money sebagai variabel moderator.

Data yang dikumpulkan bersifat data primer. Data tersebut diperoleh secara langsung dari responden yaitu mahasiswa Akuntansi S1 UNY. Responden dikumpulkan pada suatu ruangan kemudian peneliti memberikan penjelasan dan pengarahan, selanjutnya peneliti memberikan treatment kepada responden.

Instrumen yang digunakan untuk menguji hipotesis dalam penelitian ini adalah kuesioner dan permainan puzzle. Kinerja atau pencapaian kinerja seseorang diukur menggunakan permainan puzzle. Pemberian kompensasi untuk responden didasarkan pada selesai atau tidaknya puzzle yang harus disusun. Selanjutnya, untuk mengetahui tingkat kecintaan seseorang terhadap uang digunakan instrumen kuesioner. Penelitian menggunakan LOMS (Love of Money Scale) untuk mengukur tingkat kecintaan uang seseorang.

Penelitian dilakukan pada bulan Agustus 2015 sampai bulan Maret 2016. Penelitian ini dilakukan pada mahasiswa Program Studi Akuntansi S1 Fakultas Ekonomi Universitas Negeri Yogyakarta. Pelaksanaan eksperimen dilakukan pada 22 Desember 2015 serta 10, 12, dan 15 Februari 2016.

\section{Populasi-Sampel Penelitian}

Populasi pada penelitian ini adalah mahasiswa tingkat $\mathrm{S} 1$ program studi Akuntansi di Universitas Negeri Yogyakarta. Sampel pada penelitian ini adalah mahasiswa program studi Akuntansi UNY angkatan 2012, 2013, 2014, dan 2015. Peneliti menetapkan sampel berjumlah minimal 20 responden untuk setiap angkatan sehingga total sampel yang dibutuhkan adalah 80 responden. Teknik pengambilan sampel yang digunakan adalah simple random sampling. Simple random sampling adalah teknik pengambilan anggota sampel yang dilakukan secara acak. 


\section{JURNAL NOMINAL / VOLUME V NOMOR 2 / TAHUN 2016}

Peneliti menggunakan desain faktorial $5 \times 2$ between subjects factorial. Faktor pada desain penelitian eksperimen ini terdiri dari skema kompensasi sebagai variabel independen, kinerja sebagai variabel dependen, dan love of money sebagai variabel moderator. Berikut desain eksperimen yang memuat perlakuan antara lima skema kompensasi dan love of money (LOM) pada kelompok responden.

Tabel 1. Kondisi Eksperimen 5x2 Between Subjects Design

\begin{tabular}{|lcc|}
\hline \multicolumn{1}{|c}{$\begin{array}{c}\text { Skema } \\
\text { Kompensasi }\end{array}$} & Low LOM & High LOM \\
\hline Bonus & $\begin{array}{c}\text { Perlakuan } \\
1\end{array}$ & $\begin{array}{c}\text { Perlakuan } \\
6\end{array}$ \\
\hline Denda & $\begin{array}{c}\text { Perlakuan } \\
2\end{array}$ & $\begin{array}{c}\text { Perlakuan } \\
7\end{array}$ \\
\hline $\begin{array}{l}\text { Bonus dan } \\
\text { Denda }\end{array}$ & $\begin{array}{c}\text { Perlakuan } \\
3\end{array}$ & $\begin{array}{c}\text { Perlakuan } \\
8\end{array}$ \\
\hline Clawback & $\begin{array}{c}\text { Perlakuan } \\
4\end{array}$ & $\begin{array}{c}\text { Perlakuan } \\
9\end{array}$ \\
\hline Netral & Perlakuan & Perlakuan \\
& 5 & 10 \\
\hline
\end{tabular}

Peneliti memberikan perlakuan kepada 5 (lima) kelompok responden yaitu kelompok skema kompensasi bonus, skema kompensasi denda, skema kompensasi bonus dan denda, skema kompensasi clawback. Satu kelompok menjadi kelompok kontrol yaitu kelompok netral.

Instrumen diberikan kepada responden secara merata tanpa memandang skema kompensasi yang diberikan. Responden dan skema kompensasi dipilih secara acak sehingga peneliti tidak memberikan eksperimen sesuai tingkat love of money responden dan responden tidak mengetahui skema kompensasi apa yang dijalani.

Responden mengisi data demografi pada kuesioner terlebih dahulu kemudian menjawab pertanyaan pada kuesioner. Selanjutnya responden diminta menyelesaikan permainan puzzle dalam waktu yang sudah ditentukan. permainan puzzle yang sama. Hasil permainan puzzle ditulis pada kuesioner,

Semua responden dengan 5 (lima) skema kompensasi yang berbeda-beda akan mengikuti beberapa tahap eksperimen. Tahapan tersebut adalah (1) peneliti memperkenalkan diri dan menjelaskan tujuan penelitian, (2) responden dalam ruang laboratorium komputer dibagi dalam 5 kelompok yang dipilih secara acak dengan 5 skema kompensasi yang berbedabeda, (3) peneliti memberikan penjelasan secara lisan mengenai pengisian instrumen yang digunakan, (4) peneliti membagikan amplop yang berisi gaji pokok dan kuesioner kepada tiap responden, (5) responden mengisi data demografi yang tertera pada kuesioner dan dilanjutkan dengan mengisi kuesioner, (6) setelah pengisian kuesioner selesai, responden diminta mengerjakan permainan puzzle menggunakan aplikasi yang sudah ada pada komputer, (7) responden diberikan waktu untuk dua kali percobaan sebagai 


\section{JURNAL NOMINAL / VOLUME V NOMOR 2 / TAHUN 2016}

pengenalan permainan puzzle dan untuk menghindari adanya kesalahan teknis, (8) selanjutnya, responden diminta segera memulai permainan puzzle dimulai dari puzzle pertama. (9) hasil ketercapaian level pada permainan puzzle akan muncul pada layar komputer lalu responden diminta menulis hasil tersebut pada kuesioner, (10) peneliti akan memeriksa setiap kelompok responden yang berhasil dan gagal mencapai target penyelesaian puzzle. Apabila berhasil maka responden akan mendapatkan bonus sesuai dengan skema kompensasi yang dijalankan, begitu pula untuk responden yang gagal akan menerima denda sesuai dengan skema kompensasi yang ia terima. Eksperimen dirancang kurang lebih 30 menit yang dimulai dari langkah pertama.

Uji hipotesis yang digunakan adalah uji hipotesis dengan Two Ways ANOVA. Penggunaan uji hipotesis ini ditujukan untuk penelitian yang memiliki satu variabel independen, satu variabel dependen, dan satu variabel moderator. Pada uji ini dilakukan analisis hubungan moderator antar variabel kategori independen dengan cara melakukan interaksi antar variabel independen (Ghozali, 2013: 81).

\section{HASIL PENELITIAN}

DAN PEMBAHASAN

\section{Skema Kompensasi Berpengaruh terhadap Kinerja}

Pada skema kompensasi bonus, bonus mempengaruhi responden dalam hal ini memberikan motivasi kepada mahasiswa untuk menunjukkan kinerja yang baik. Hal tersebut mendukung penelitian Luft (1994) dan Hanan et al., (2004) bahwa karyawan lebih cenderung memberi kinerja yang baik pada kontrak bonus.

Skema kompensasi denda memiliki pengaruh terhadap kinerha. Hasil tersebut mendukung penelitian Hanan et al., (2004) bahwa denda memiliki pengaruh terhadap kinerja. Pada penelitian ini mahasiswa memberikan kinerja yang baik untuk mencapai target. Upaya mencapai target tersebut dilakukan agar mereka terhindar dari denda yang banyak. Namun terdapat perbedaan hasil penelitian dari Hanan et al., (2004) yang menyebutkan kinerja pada kontrak denda lebih tinggi daripada kontrak bonus. Pada penelitian ini kinerja pada skema bonus lebih tinggi daripada kinerja pada skema denda.

Skema kompensasi bonus dan denda memiliki pengaruh pada kinerja. Hasil ini mendukung penelitian Brink dan Rankin (2013) bahwa responden menyukai skema kompensasi bonus dan denda. Kombinasi skema bonus dan denda dianggap adalah skema kompensasi yang adil. Responden 


\section{JURNAL NOMINAL / VOLUME V NOMOR 2 / TAHUN 2016}

berupa mahasiswa memberikan kinerja terbaiknya agar terhindar dari denda dan sebagai imbalannya akan menerima bonus sesuai dengan level di atas target yang dapat diselesaikannya.

Hasil pengujian menunjukkan bahwa skema kompensasi clawback berpengaruh terhadap kinerja. Pada penelitian Brink dan Rankin (2013) menyebutkan bahwa skema clawback kurang atraktif dibandingkan skema kombinasi bonus dan denda dan skema bonus atau denda saja. Namun pada penelitian ini nilai mean skema kompensasi clawback menunjukkan kinerja terbaik dibandingkan dengan skema bonus, skema denda, serta skema bonus dan denda. Hal tersebut merupakan dampak dari teori endowment effect dimana seseorang menilai tinggi sesuatu yang telah dimilikinya sehingga responden melakukan upaya terbaiknya untuk mencapai target dan mempertahankan apa yang sudah diterimanya.

\section{Tabel 2. Hasil Pengujian Skema}

Kompensasi Berpengaruh terhadap Kinerja

\begin{tabular}{|lccc|}
\hline \multicolumn{1}{|c}{$\begin{array}{c}\text { Skema } \\
\text { Kompensasi }\end{array}$} & Signifikansi & F & Mean \\
\hline Bonus & 0,03 & 4,90 & 3,00 \\
\hline Denda & 0,01 & 6,22 & 2,88 \\
\hline $\begin{array}{l}\text { Bonus \& } \\
\text { Denda }\end{array}$ & 0,04 & 4,34 & 3,00 \\
\hline Clawback & 0,02 & 5,95 & 3,11 \\
\hline
\end{tabular}

\section{Love of Money Memoderasi Pengaruh}

\section{Skema Kompensasi terhadap Kinerja}

Love of money memiliki pengaruh moderat pada pengaruh skema kompensasi bonus terhadap kinerja. Mahasiswa dengan sikap love of money termotivasi memberikan kinerja terbaik untuk mendapatkan imbalan moneter. Hal tersebut didukung oleh penelitian Monteiro, et al. (2015) bahwa perilaku positif dari love of money diwujudkan dalam bentuk usaha untuk mendapatkan reward.

Love of money tidak memiliki pengaruh moderat pada pengaruh skema kompensasi denda terhadap kinerja. Penelitian Brink dan Rankin (2003) menyebutkan skema denda saja tidak menarik bagi responden. Sama halnya dengan mahasiswa dengan sikap love of money tidak memotivasi kinerja mereka dalam skema kompensasi denda ini.

Love of money tidak memiliki pengaruh moderat pada pengaruh skema kompensasi kombinasi bonus dan denda terhadap kinerja. Hal tersebut dibuktikan dari nilai signifikansi yang lebih dari 0,05. Hasil itu juga bersebrangan dengan pernyataan pada penelitian Tang dan LunaArocas (2005) yang menjelaskan bahwa seseorang dengan love of money membutuhkan tingkat kepuasan kerja dan aktualisasi diri yang tinggi. Melalui skema bonus dan denda seseorang bisa mendapatkan bonus yang besar. 


\section{JURNAL NOMINAL / VOLUME V NOMOR 2 / TAHUN 2016}

Love of money memiliki pengaruh moderat pada pengaruh skema kompensasi clawback terhadap kinerja. Brink dan Rankin (2013) menjelaskan endowment effect yaitu keengganan kehilangan atas apa yang sudah dimiliki. Responden memberikan kinerja terbaiknya untuk mempertahankan imbalan moneter yang sudah didapatkan. Akibat dari endowment effect, seseorang dengan love of money mempertahankan bonus yang sudah dimilikinya dalam skema clawback ini untuk menghindari kehilangan.

Tabel 3. Hasil Pengujian Love of Money Memoderasi Pengaruh Skema Kompensasi terhadap Kinerja

\begin{tabular}{|lccc|}
\hline \multirow{2}{*}{$\begin{array}{l}\text { Skema } \\
\text { Kompensasi }\end{array}$} & \multicolumn{3}{c|}{ Love of Money } \\
\cline { 2 - 4 } & Signifikansi & $\mathrm{F}$ & Mean \\
\hline Bonus & 0,03 & 5,50 & 3,00 \\
\hline Denda & 0,34 & 0,94 & 2,88 \\
\hline $\begin{array}{l}\text { Bonus \& } \\
\text { Denda }\end{array}$ & 0,20 & 1,72 & 3,00 \\
\hline Clawback & 0,01 & 7,25 & 3,11 \\
\hline
\end{tabular}

\section{SIMPULAN DAN SARAN}

\section{Simpulan}

Keempat skema kompensasi yakni skema kompensasi bonus, denda, bonus dan denda, serta clawback memiliki pengaruh terhadap kinerja. Kinerja tertinggi berada pada skema kompensasi clawback yang ditunjukkan dari nilai mean tertinggi dibandingkan nilai mean skema kompensasi lainnya.
Pernyataan yang diterima adalah love of money memoderasi pengaruh skema kompensasi bonus dan clawback terhadap kinerja, sedangkan pernyataan yang ditolak adalah love of money memoderasi pengaruh skema kompensasi denda serta kombinasi bonus dan denda terhadap kinerja.

\section{Saran}

Saran yang dapat diberikan bagi penelitian selanjutnya adalah pemilihan subjek sebaiknya diperluas dari segi kuantitas agar tidak menimbulkan perbedaan persepi yang dapat mempengaruhi hasil penelitian, subjek penelitian dalam satu ruangan eksperimen idealnya hanya diberikan satu skema kompensasi saja agar peneliti dapat menyampaikan treatment lebih jelas, selanjutnya apabila penelitian selanjutnya menggunakan aplikasi, peneliti dapat bekerjasama dengan seseorang yang ahli dalam bidang IT. Aplikasi yang digunakan dapat dikembangkan dan diperbaiki sesuai dengan karakteristik subjek penelitian sehingga dapat mencerminkan kinerja responden secara keseluruhan.

Bagi praktisi bisnis, dilihat dari hasil penelitian ini dimana skema kompensasi clawback memiliki kinerja terbaik dibandingkan skema kompensasi lainnya menunjukkan bahwa kinerja yang baik dapat diperoleh melalui rangsangan bonus dengan tuntutan mencapai target. 


\section{JURNAL NOMINAL / VOLUME V NOMOR 2 / TAHUN 2016}

Selanjutnya skema kompensasi denda yang memiliki kinerja terendah menunjukkan bahwa seseorang tidak dapat memberikan kinerja terbaiknya apabila bekerja di bawah tekanan. Maka skema kompensasi yang menerapkan bonus adalah baik untuk diterapkan dengan tujuan agar memotivasi seseorang memberikan kinerja terbaiknya. Seseorang dengan kecintaanya terhadap uang akan lebih termotivasi pada skema kompensasi bonus dan skema kompensasi clawback. Apabila menerapkan skema kompensasi yang mengandung unsur bonus maka hal tersebut dapat digunakan untuk meningkatkan kinerja seseorang.

\section{DAFTAR PUSTAKA}

Anoraga, Pandji dan Sri Suyati. Perilaku Keorganisasian. (1995). Jakarta: PT Dunia Pustaka Jaya.

Brink, Alisa G \& Frederick W. Rankin. (2013). "The Effects of Risk Preference and Loss Aversion on Individual Behavior under Bonus, Penalty, and Combined Contract Frames." Behavioral Research in Accounting, Vol 25, 145170.

Energy Today. (2015). "Pekerja Freeport 7 Suku Mogok Kerja Tuntut Bonus dan Kompensasi." Diakses tanggal 17 Mei

Ghozali, Imam. (2013). Aplikasi Analisis Multivariate dengan program IBM SPSS 21.” Edisi 7. Semarang: Badan Penerbit Universitas Diponegoro.

Hanan, R. Lynn., Vicky B. Hoffman, \& Donald V. Moser. (2005). "Bonus Versus Penalty: Does Contract Frame Affect Employee
Effort?" Experimental Business Research, Vol 20.

Energy Today. (2015). "Pekerja Freeport 7 Suku Mogok Kerja Tuntut Bonus dan Kompensasi." Diakses tanggal 17 Mei

Ghozali, Imam. (2013). Aplikasi Analisis Multivariate dengan program IBM SPSS 21.” Edisi 7. Semarang: Badan Penerbit Universitas Diponegoro.

Hanan, R. Lynn., Vicky B. Hoffman, \& Donald V. Moser. (2005). "Bonus Versus Penalty: Does Contract Frame Affect Employee Effort?" Experimental Business Research, Vol 20.

Hartono, Jogiyanto. (2013). Metodologi Penelitian Bisnis. Edisi 5. Yogyakarta: BPFE.

Kadarisman, M. (2012). Manajemen Kompensasi. Jakarta: Rajawali Pers.

Luft, Joan. (1994). "Bonus and Penalty Incentives Contract Choice by Employess." Journal of Accounting and Economics, 18, 181-206.

Monteiro, Danielli Leite Campos, et al. (2015). “Attitudes Towards Money and Motivational Orientation to Work in Brazilian Young Workers.” pp 11-30.

Nawawi, Hadari. (2006). Evaluasi dan Manajemen Kinerja di Lingkungan Perusahaan dan Industri. Cetakan Pertama. Yogyakarta: Gadjah Mada University Press.

Tang, Thomas Li-Ping, David Shin-Hsiung Tang, \& Roberto Luna-Arocas. (2005). "Money Profiles: The Love of Money, Attitudes, and Needs." Personnel Review, Vol. 34, 603-618 